\title{
On predicting animal evolution
}

\author{
Stuart P. Norman \\ nwnature@microlink.zm \\ North-West Naturalists' Society of Zambia \\ P.O. Box 60462, Livingstone, Zambia, south-central Africa
}

\begin{abstract}
The origination of most free-living animal species is predictable. 'Light' order in the producer trophic levels below is the key. Absent from the abiotic environment (pre-biotic level) and prokaryotes, 'light' order consists of differences in species composition between developed species-packed communities in which extinction may be the precursor of speciation, particularly ecologically comparable tropical lowland ones of Africa, Australia, India, and South America. Based on but not itself of matter and non-burnable, nil waste heat content 'compensates' for burned-up food energy. Where the amounts on pre-apical levels form an inverted pyramid like waste heat's, occupancy of consumer levels from primary to apical is predictable (variation and selection assumed). Terminal non-inversion predicts postapical vacancy. Examined communities were from grasslands (large carnivores, large grazing mammals, grasses) and woodlands (raptorial birds, insect-eating birds, butterflies, woody plants). Comparisons with Darwin's and Lyell's non-predictive theories of change are made. Implication for Gladyshevian thermodynamics $v$. Prigoginean dynamics is discussed. Linnaeus's classificational system turns out to be rich with new and unsuspected content.
\end{abstract}

Key words: extinction - 'light' order - Linnaean system - thermodynamics - trophic levels tropical lowland communities

\section{INTRODUCTION}

Lyell's doctrine of uniformitarianism ${ }^{1-2}$ replaced Cuvier's catastrophe theory and strongly influenced the young Charles Darwin. Both it and Darwin's theory of common descent by natural selection ${ }^{3}$ supplied frameworks for ordering observations, but were weak predictively. Consequently the origin of species seemed non-predictable. ${ }^{4}$ The present aim is to show that the origination of most free-living animal species is predictable under carefully defined conditions.

Trophic pyramids summarise large masses of observations about the numbers and kinds of organisms in a community and their feeding relations. Since they contain time, they should be predictive; but those adduced were vitiated by what they left out. Thus, Elton's pyramid of animal numbers ${ }^{5}$ neglected plants; Lindeman's pyramid of potential energy ${ }^{6}$ eliminated the wealth of species in favour of a common physical denominator, energy.

\section{MATERIALS AND METHODS}

Our primary material will be order. I distinguish two kinds, viz. 'heavy' and 'light' order. Species diversity is the stuff from which 'heavy' order is made. It is reducible to DNA and proteins, whereas 'light' order consists of differences in species composition only and is therefore matter-free, meaning it cannot be burned. Since it cannot be burned, it potentially contains no waste heat. Its grade purity qualifies it in some not as yet fully understood way to 'compensate' for burned-up energy losses in those ecosystems that contain enough of it. 'Enough' is here defined as: when the amounts of 'light' order on successive trophic levels 
make an inverted pyramid similar in shape to waste heat's additive one, with the pre-primary level or abiotic environment keeping unchanged its pre-biotic value of zero. Predicting the occupancy / vacancy of a consumer level thus turns on knowing the amounts of 'light' order on the two levels below, heritable variation and natural selection being assumed favourable in the former alternative's case. Pyramid height, or the number that is assigned to the apex predator level is not predictable by this means.

Exemplary ecosystems and communities are located in ex-Gondwana plates that drifted apart by seafloor spreading to form the southern continents and India. ${ }^{7}$

Although relative extinction, speciation, and dispersal rates determine comparative composition within a trophic level, comparison of standing difference patterns over several levels will be our concern.

Tropical lowland woodlands, forests (no data available), and grasslands are most favourable, because their climax communities were least affected by glacial wipeout. ${ }^{8} \mathrm{Within}$ these highly-developed, species-packed communities, there may be a tendency for speciation to follow extinction rather than precede it as new forms evolve very largely to replace those adaptively fallen behind with time and change. Both steps together are a zero-sum for biomass, whence the epithet 'light.' Each contributes a point to compositional differences between communities across the intercontinental divide that once had a common boundary and genetic heritage. A quantity of 'light' order is thus produced for no net change to biomass but a high cost genetically.

Within each tropical biome, three pairwise comparisons were made, namely and respectively: Africa (Afr) $v$. South America (S Am); Afr $v$. India (Ind); and Afr $v$. Australia (Aus). Afr is common, because I lack first-hand experience of the others. The grassland ecosystem comprised three trophic levels:- large carnivores, large grazing mammals, grasses. Compositional data were obtained by extracting information from existing works. ${ }^{9-11}$ The woodland ecosystem had four trophic levels:- raptorial birds, insect-eating birds, butterflies, woody plants. The choice of the butterflies was for their specific larval host-plant preferences and the close degree of adaptation to the plant life in a locality that these imply.

Compositional data were obtained by direct study of two south-central Afr savanna woodland sites over a 6-year period. ${ }^{12}$ They were a 0.5 hectare area of Kalahari Sand woodland dominated by Baikiaea plurijuga Harms on deep windblown deposits of Pleistocene age, and a 26 hectares area of floristically richer Escarpment woodland on stony soils over Karoo basalt. Both sites were near Livingstone, Zambia. Neither one was insular, as the first was flanked and backed and the second was surrounded by a much larger expanse of similar environment.

The width of a trophic level in a pairwise-comparison pyramid - hereafter, 'difference pyramid' - was defined as the percent difference in species composition at that particular level. In the case of extremely large compositional differences at one or more trophic levels, comparative examination may take place at the next higher level of taxonomy, i.e. the genus.

The pyramidiform shapes that resulted from vertically stacking their trophic levels as defined were described, comparisons with Eltonian and Lindemanian pyramids were made, and interesting differences were noted.

\section{RESULTS}

i. Tropical lowland grasslands

These difference pyramids differed from Eltonian and Lindemanian pyramids by being inverted in shape below, and changing to normal at, the apical consumer level. The latter was intermediate in width between the primary producer and primary consumer levels. In detail:- 
Primary producer level. ${ }^{9-10}$ Compositional similarities are numerous, at the genus level especially. Thus, out of 120 genera of grasses (Gramineae) in one south-central Afr territory, Zambia, no fewer than 41 (34\%) also occur in all three of S Am, Ind, and Aus and around one-half have representatives in each (S Am 46\%, Ind 56\%, Aus 51\%).

Primary consumer level. ${ }^{11}$ Compositional differences of high taxonomic rank abound. Thus Aus grazers are marsupials (kangaroos, wallabies). Of placentals, hydrochoerids (capybaras) are in S Am only, grazing suids (warthogs) and hippopotamids (hippopotami) in Afr only. Tropical Afr lacks cervids (deer), while Ind forms (Cervinae) differ at the subfamily level from S Am ones (Capreolinae). Ind and Afr share elephantids (elephants), rhinocerotids (rhinoceroses), equids (wild asses, zebras), and bovids (antelopes, buffaloes), but their genera are nearly all different.

Secondary (=apical) consumer level. ${ }^{11}$ Compositional differences are low to moderately high. Crocodiles Crocodylus are in all four areas, great cats Panthera in all except Aus. Striped hyaena Hyaena and cheetah Acinonyx are common to Ind and Afr. The remainder are genuslevel or higher. Thus alligatorids (as caimans Caiman) and the only large-sized Felinae (puma Puma) are in S Am only, hyaenids and acinonychine felids in Ind and Afr only (but spotted hyaena Crocuta not in Ind). Compare S Am boids (boa constrictor, anaconda) with Aus, Ind, and Afr pythonids (pythons), and S Am bush dog Speothos with Aus dingo Canis, Ind dhole Cuon and wolf Canis, and Afr hunting dog Lycaon.

ii. Tropical lowland woodlands

These difference pyramids differed from Eltonian and Lindemanian pyramids by being inverted in shape below, and changing to normal at, the apical consumer level. The latter was intermediate in width between the primary producer and primary consumer levels. In numerical detail (Figure 1, based on information in Annexes 1 and 2). ${ }^{12}$

Figure 1, in: On predicting animal evolution, by Stuart P. Norman

\begin{tabular}{lllllll}
\hline Trophic level & \multicolumn{3}{c}{ 0.5ha Afr site } & \multicolumn{4}{c}{ 26ha Afr site } \\
& \% genera not shared with & \multicolumn{3}{c}{ \% genera not shared with } \\
& S Am & Ind & Aus & S Am & Ind & Aus \\
\hline Raptorial birds & 69 & 38 & 54 & 71 & 43 & 57 \\
Insect-eating birds & 98 & 58 & 80 & 97 & 58 & 79 \\
Butterflies & 88 & 41 & 61 & 89 & 46 & 66 \\
Woody plants & 55 & 30 & 52 & 60 & 36 & 49 \\
\hline
\end{tabular}

Fig. 1. Two difference pyramid sets from the tropical woodland biome. Trophic level width is directly proportional to percent difference. In each set, the data permit the inference that the four trophic levels were drawn from different populations with regard to mean ranks (Friedman two-way analysis of variance, $\chi^{2}{ }_{r}=9, P=.0017$ ).

\section{DISCUSSION}

Of the two regularities reported here, one, the ordinally unchanging width position of the apical consumer level between the primary producer and primary consumer levels, is unaccountable. The second, the repeating inverse-pyramid pattern of the infra-apical trophic levels, will therefore occupy our attention exclusively below.

Considering the trophic level relation

width $\propto 1 /$ height 
of an Eltonian or a Lindemanian pyramid, the width decrease implication of a height increase implies nothing as to the probability of a higher-level predator's evolving. Clearly, their predictive power is nil. 'Light' order, on the other hand, is highly predictive. Thus, whenever a consumer level in a difference pyramid followed a width increase on the producer levels below, it was found to be occupied (assuming the availability of heritable variation in the 'right' direction and natural selection for effectiveness in the new role); but not otherwise.

Functionally, a difference pyramid resembles a well-posted highway. Along it, energy, and very occasionally genes, move on their passage through the ecosystem. Each infra-apical trophic level displays a green sign for 'Go.' The green signs keep the "traffic moving" as far as the apical level, where a red 'Stop' sign arrests further movement. This 'light' order perspective differs from the customary view, which (rightly) sees obstacles to the flow of energy arising at every level as the occupants come under selective pressure to evolve new and better ways of avoiding being eaten by those on the next level up. "An ecosystem, as a machine, is highly inefficient for just this reason, the impediments raised by each trophic level to the passage of energy to the next higher level." 13 And the highway itself: how did it arise? For an impartial perspective, let us suppose that a military engineer is tasked with rebuilding a strategically important bridge and for constructive material lights on the same substance as the enemy used, i.e. dynamite. Obviously, the replacing structure was going to be thermodynamically highly unstable. Something of the sort is implied whenever the theory of natural selection and nothing else besides is called upon to explain how the very first occupant of any given consumer level originated; while similar arguments apply to the descendants of all, including the species happenstance flings together at a named time and place to make a functional community. A serviceable highway construction (non-)material, on the other hand, is furnished by 'light' order. Thus, while I continue firmly to believe that these species, as instanced here by the butterflies, insect-eating birds, and raptors, capybaras and jaguars, deer and tigers, and zebras and lions of the continental lowland tropics of today, evolved with the aid of the process of natural selection, I now doubt whether they could have evolved by it alone.

In neoDarwinian theory, mutation, recombination, and selection would be sufficient for free-living animals like these to evolve. ${ }^{4,13}$ The inference to be drawn from the present findings is that they are insufficient, in the specific context of the advanced stage of ecosystem growth and development which these particular species and their communities represent.

It actually is possible to demonstrate that, in this same stage of community growth and development, a certain amount of 'light' order goes into making any one animal species of this kind, and the amount of it moreover is measurable (in prep.).

Three major problem areas of biology and evolution which this approach to animal evolution goes some or all of the way towards resolving are the following: 1. "The inherent strength of the [genetical] theory [of natural selection] is restricted by the paucity of generalizations, analogous to Kepler's laws, that can serve on the one hand as summaries of large masses of observations and, on the other hand, as logical deductions from the theory."13 A generalisation of this sort would be the causal chain,

$$
\text { extinction }+ \text { speciation } \rightarrow \text { 'light' order } \rightarrow \text { difference pyramids } \rightarrow \text { trophic pyramids. }
$$

It permits the deductions that in non-animals such as prokaryotes (bacteria, archaea) in which extinction appears to be unknown, ${ }^{14}$ production of 'light' order (an operational definition of which is in prep.) cannot have occurred, nor therefore can trophic pyramids of free-living consumers have risen up: and apparently they have not. Going extinct, producing 'light' 
order, and (in the case of animals) raising up trophic pyramids all seem to be specifically biparental-eukaryote phenomena. 2. "The degree of complication in biology is so discouraging that one can ... not imagine any set of concepts in which the connections could be so sharply defined that a mathematical representation could become possible." 15 However, the Linnaean system imposes on nature's exceedingly complicated and involuted arrangement a relatively simple and straightforward pattern I call the neoLinnaean, that (as difference pyramids) is amenable to both measurement and empirical demonstration. It thus appears as if the true degree of complication in biology has been exaggerated. 3. "Biology is a label for two largely separate fields ... which may be designated functional biology and evolutionary biology." "However, Linnaeus took the first and essential contra-divisive step forward when he arranged the species - the building blocks of biology - in their natural order. ${ }^{16}$ With advances in taxonomy and classification since then, the Linnaean system now turns out to fit the structure of the ecosystem - the functional unit formed by the building blocks.

The position in biology today is basically unmoved from the deadlock as Heisenberg ${ }^{15}$ and Williams ${ }^{13}$ described it over fifty years ago, while Mayr's ${ }^{4}$ functional and evolutionary biologies continue to dwell apart.

I would amend the above extracts in quotation marks from these authors to read as follows:-

1. The intrinsic strength of the theory of organic evolution is enhanced by the abundance of generalisations that can serve as summaries of large masses of observations and as logical deductions from the theory.

2. The true degree of complication in biology is so slight that one can imagine a set of concepts in which the connections could be so sharply defined that a mathematical representation could become possible.

3. Biology is no longer a label for two separate fields called functional biology and evolutionary biology. From now on it is one field.

These benefits accrue as direct consequences of incorporating Linnaeism into the fabric of ecological and evolutionary science. Past failure to do so thus appears in retrospect to have been an unforced error of colossal proportions, comparable in its consequences to the state of ignorance and helplessness that prevailed in physical science prior to Mendeleev's discovery of the periodic table of the elements.

What raises difference pyramids well above the biological average on a predictivity scale? The relation between heat, work, and information is a topic in physics but not in biology. However, that could change. Apparently the presence of 'light' order in sufficient amounts unblocks the way for the biparental eukaryote community to acquire additional complexity by ascending a time interval (feeding level). A mechanical or electrical device performs the work of lifting a mass up through a height interval. In the living system heritable variation and natural selection are responsible for performing the work of ascent (common descent); in the physical system a human worker rather than genes as such is the intelligence behind the machine. These differences aside, the superficially dissimilar set-ups are comparable. The interesting feature is that (taxonomic) information is the (non-)stuff from which 'light' order is made, 'information' in the theory of that name is inversely related to waste heat, ${ }^{17-18}$ heat is motion of matter, ${ }^{19}$ but matter forms no part of 'light' order, which is the reason why the latter is supremely well qualified to 'compensate' for waste heat. The 
astounding feature is that prediction is possible at all, when the historical nature of the subject matter and the sheer numbers of interacting variables at any one time would seem to be resolutely against it. The principal exception is the number that is assigned to the top predator level. I would expect this number to go on resisting prediction.

The predictive strength of a difference pyramid comes from its marrying of ecological pattern and the geographic-isolation model of speciation, i.e. the empirically best attested model of how most free-living animal species originate. ${ }^{4}$ As a term for the resulting overall pattern, I prefer 'macrogenetic' to 'macroecological' or 'macroevolutionary.' The prefix 'macro-' is in recognition of the fact that there may be no microgenetic basis for the extirpation of an entire genetic line, i.e. the first step in making 'light' order. If there were such a basis then extinction could be regarded as a creative factor in evolution, which it is not. ${ }^{13}$ Difference pyramids are 'neoLinnaean' as said, firstly because plants are present unlike in an Eltonian pyramid, and secondly because the currency common to all trophic levels is not, biologically speaking, energy as in a Lindemanian pyramid, but an organism's place in the binomial classification system of which Linnaeus ${ }^{16}$ is the founding father and which is (at its best) a true reflection of the process of common descent. Finally, I call the macrogenetic process 'neoLyellian,' meaning Lyell's principle of uniformity ${ }^{1-2}$ raised up to an abstract plane in which the neoLinnaean, a historically invariant pattern, replaces his steady-state principle. ${ }^{1-2}$ For this pattern admits directional change on all temporal scales:- evolutionary, as the very occasional trophic level additions to an ecological pyramid; historical, as the imperceptibly slow but comparatively steady growth of difference pyramids following the null difference state(s) or near that would have prevailed in Gondwana time; ecological, as the daily throughput of energy.

Omnivory, a problem for non-difference-based food pyramids, poses none. A difference pyramid is a system-level platform and potential for making more differences. Incipient differences should be ones of degree: a primary carnivore will not likely let go of its herbivorous past at one go. Adherence to a combined macrogenetic plus gradualist ${ }^{4}$ adaptive model positively requires that some animal species possessed of trophically intermediate characteristics be around.

The macrogenetic model of animal evolution applies to the plants and animals of a named time and place. Consequently it is refutable by inspection of particular times and places. A statistical model, it relies on fairly large numbers of species being present. Consequently it might not apply to inchoate or impoverished communities, such as those of small islands and early stages in ecological succession. It could be zoologically limited, as $\approx 40 \%$ of all animal species are parasitic. ${ }^{20}$ Whether or not it applies to these as well as their free-living hosts, is presently unknown. Then there are free-living forms that live off parasites, e.g. oxpecker birds Buphagus whose diet consists largely of haemophagous ectoparasites gleaned from large herbivores. Finally, a small minority apparently has evolved in the reverse direction to a difference pyramid's, e.g. the giant panda Ailuropoda is an aberrant member of the order Carnivora that has undergone secondary reversion to herbivory. This model could not have predicted the origins of animals such as these.

'Light' order is a non-consumable global resource. Unlike potential energy, it cannot be dissipated, but is continually being destroyed and created. It is not recyclable (but is 'reusable' over and over again, though it be never the same river twice, like that of Heraclitus). The other major external energy source in its production besides the sun is the heat in the earth's core. The di-energetic basis of a difference pyramid helps explain its inverted shape below the apical level, like that of a river that runs through a well-watered land and grows in discrete steps by capturing new tributaries at intervals as it goes. The 
mono-energetic Eltonian and Lindemanian alternates resemble feederless desert streams by comparison.

'Compensation' is macroscopic, but what of the distribution of underlying microstates, i.e. is it reducible to statistical mechanics? What is the equation that expresses quantitatively the relation between waste heat (thermal disorder) on the one side and 'light' order on the other side (the two regularities reported here imply it exists)? Is the character of the neoLyellian process as a whole Prigoginean (fluctuational-bifurcational), ${ }^{21}$ or is it Gladyshevian (hierarchical-thermodynamic) ${ }^{22}$ ? In Gladyshev's law of temporal hierarchies, $\mathbf{t}$ is the average life-span of biological structures:

$$
<<\mathbf{t}^{\mathrm{mol}}<<\mathrm{t}^{\mathrm{cel}}<<\mathbf{t}^{\mathrm{org}}<<\mathrm{t}^{\mathrm{pop}} \ldots<<\left[\mathbf{t}^{\mathrm{nL}}\right]
$$

where mol to pop stand for his molecule, cell, organism, and population levels respectively and $[\mathbf{n L}]$ for neoLinnaean is my insert. The antiquity of the latter is $\approx 10^{8} \mathrm{y}$. Whether its Gibbs function ${ }^{22}$ tends to a minimum, like most of the others', ${ }^{22}$ is undetermined. My 'macrogenetic' echoes Gladyshev's 'macrothermodynamic.' For him, biological phenomena are consistent with non-Prigoginean, Carnot-Gibbs-Clausius-Boltzmann-Thomson thermodynamics. However, a heat-engine model of the ecosystem, with its alternation between heated and cooled states, ${ }^{21}$ is inappropriate to the last hierarchical structure. On the other hand, the furnace in the earth is a constantly 'on' heat source that more closely resembles the hot plate in the Bénard cell model. ${ }^{21}$ It underpins the evolution of the neoLinnaean. Prigogine's model of fluctuations leading to bifurcations ${ }^{21}$ also seems to fit well the splittings of trophic levels that took place at various times during the ascent of the biparental eukaryotes, as early herbivore-like and plant-like forms separated out to form the first difference pyramids, and so forth.

\section{CONCLUSION}

Linnaeus ${ }^{16}$ invented the scientific language with which to describe a cross-section through the living world as it exists at any given moment, such as the present. NeoDarwinism provides the underlying mechanism ${ }^{4,13}$ and molecular phylogenetics the investigative tools to explain how it evolved. So far these last have proceeded as if they had the description in their grasp, meaning, of course, the familiar icon of the evolutionary tree of life. But the cross-sectional figure of the neoLinnaean is orthogonal to the latter. So the number of descriptions has gone from one to two: the one 'vertical' and sprouting 'horizontal' branches in an apparently haphazard manner in morphological space, the other 'horizontal' and giving rise to a 'vertical' pattern of orderly growth and development in trophic time. Both describe common descent, the one in particulate fashion, the other using an averaging method. The one focuses on adaptations of species, ${ }^{13}$ the other on species exclusive of their adaptations. The one examines gradual change to gene frequencies in an interbreeding population, ${ }^{4,13}$ while the other examines patterns of disappearance and first appearance of entire species and higher categories in a system comprising three distinct biotic areas of which the middle one is a barrier of immense size and age. The one is applicable to all living things at all times, the other to how a subset of comparative latecomers and their descendants have turned out. The one is static and afunctional, the other dynamic and functional. The one is non-predictive, the other predictive. The futility of arguing for the 'superiority' of either description will be evident. They are complementary, not alternative; both are necessary to a complete biological description. And yet the neoLinnaean is the only one to impose, in the parts of the evolutionary tree where it is applicable, severe restrictions on the possible states of systematic 
affairs. It is also the only one to expose itself nakedly to refutation by being thus and so and not otherwise; and the possibilities for comparing it with experience are practically endless.

\section{ETHICAL STATEMENT}

Field work was carried out as part of my duties with North-West Naturalists' Society of Zambia, a registered non-governmental organisation.

\section{COMPETING INTERESTS}

I have no competing interests.

\section{ACKNOWLEDGEMENTS}

My wife Meamui L. Akayombokwa assisted in the field and otherwise supported the work in crucial ways throughout. This paper is dedicated to her. North-West Naturalists' Society of Zambia arranged a work permit. Mike Bingham determined many plants and read through several manuscript versions, as did Ken Scott. Dr. David Goyder of Kew Gardens identified Stomatostemma monteiroae. To each of you, my gratitude.

\section{FUNDING}

I am an independent researcher. No outside funding was used in this research.

\section{REFERENCES}

1. Lyell C. 1830-1833. Principles of geology. London: John Murray.

2. Camardi M. 1999. Charles Lyell and the uniformity principle. Biology and Philosophy, 14 (4): 537-560. https://doi.org/10.1023/A:1006504910017

3. Darwin C. 1859. On the origin of species by means of natural selection. London: John Murray.

4. Mayr E. 1997. Evolution and the diversity of life. Cambridge MA: Harvard University Press.

5. Elton C. 1927. Animal ecology. London: Sidgwick \& Jackson.

6. Lindeman RL. 1942. The trophic-dynamic aspect of ecology. Ecology, 23: 399-418.

7. Torsvik TH, Cocks LRM. 2013. Gondwana from top to base in space and time. Gondwana Research, 24: 999-1030. http://dx.doi.org/10.1016/j.gr.2013.06.012

8. Pfefferkorn HW, Gastaldo RA, Dimichele W. 2017. Impact of an icehouse climate interval on tropical vegetation and plant evolution. Stratigraphy, 14 (1-4): 365-376. DOI:

10.29041/strat.14.1-4.365-376

9. Flora Zambesiaca Managing Committee. 1971-2002. Gramineae. Flora Zambesiaca, 10. Kew: Royal Botanic Gardens.

10. Gibbs Russell GE, Watson L, Koekemoer M, Smook L, Barker NP, Anderson HM, Dallwitz MJ. 1990. Grasses of southern Africa. Memoirs of the Botanical Survey of South Africa No. 58. http://trove.nla.gov.au/version/45808516

11. Darlington PJ Jr. 1957. Zoogeography. New York: Wiley.

12. Annexes 1 and 2. Uploaded as Supplemental material.

13. Williams GC. 1966. Adaptation and natural selection. Princeton: Princeton University Press.

14. Cockell CS. 2003. Impossible extinction: natural catastrophes and the supremacy of the microbial world. Cambridge: Cambridge University Press.

15. Heisenberg W. 1990. Physics and philosophy. London: Penguin.

16. Linnaeus C. 1758. Systema naturae. $10^{\text {th }}$ ed. Stockholm: Salvius.

17. Jaynes ET. 1957. Information theory and statistical mechanics. Phys. Rev., 106 (4): 620630. Bibcode: $1957 \mathrm{PhRv} . .106 . .620 \mathrm{~J}$. doi: $10.1103 /$ PhysRev.106.620 
18. Jaynes ET. 1957. Information theory and statistical mechanics II. Phys. Rev., 108 (2): 171-190. Bibcode: 1957PhRv..108..171J. doi:10.1103/PhysRev.108.171. 19. Maxwell JC. 1871. Theory of Heat. London: Longmans, Green, \& Co.

20. Dobson A, Lafferty KD, Kuris A, Hechinger R, Jetz W. 2008. Homage to Linnaeus: How many parasites? How many hosts? Proc. Natl. Acad. Sci. USA, 105 (Suppl. 1): 11482-11489. 10.1073/pnas.0803232105

21. Prigogine I, Stengers I. 1984. Order out of chaos. London: Flamingo. 22. Gladyshev GP. 2005. The Second Law of Thermodynamics and the evolution of living systems. Journal of Human Thermodynamics, 1: 68-81. 